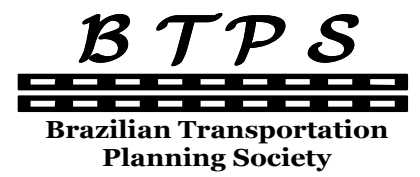

Journal of Transport Literature

Vol. 7, n. 3, pp. 59-86, Sep. 2013

Research Directory

JTL|RELIT

www.transport-literature.org
ISSN 2238-1031

\title{
Linking activity participation, socioeconomic characteristics, land use and travel patterns: a comparison of industry and commerce sector workers
}

[Relações entre participação em atividades, características socioeconômicas, uso do solo e padrões de viagens:
uma comparação entre trabalhadores nos setores industrial e comercial]

\author{
Cira Souza Pitombo*, Eiji Kawamoto, Antonio Jorge Gonçalves de Sousa
}

Federal University of Bahia - Brazil, University of São Paulo - Brazil, Technical University of Lisbon (TULisbon) - Portugal

Submitted 11 Jun 2012; received in revised form 29 Oct 2012; accepted 11 Nov 2012

\begin{abstract}
The objective of this work is to analyze the travel behavior of industry and commerce sector workers in terms of three variables groups: activity participation, socioeconomic characteristics and land use. This work is based on the Origin-Destination survey carried out in the São Paulo Metropolitan Area (SPMA) in 1997. Relationships were found between the concerned variables (Decision Tree), and the statistical significance of independent variables was assessed (Multiple Linear Regression). We analyzed the influence of the three variables groups on travel pattern choices: (A) socioeconomic variables (Household Income, Transit Pass Ownership and Car-ownership) affect the travel mode sequence; (B) activity participation (Study, Work) has an effect on the trip purpose sequence; and (C) land use variables (accumulated proportion of jobs by distance buffers starting from the home traffic zone centroid) influence the sequence of destinations chosen, especially in the case of industry sector workers. The different spatial distributions of economic activities (commercial and industrial) in the urban environment influence the travel of workers. This paper contributes essentially proposing the land use variable, through the intervening opportunities model as well as the presentation of a methodology, formed by application of exploratory and confirmatory techniques of multivariate data analysis.
\end{abstract}

Key words: travel behavior, land use, activity participation, socioeconomic variables.

\section{Resumo}

O objetivo deste trabalho é analisar o comportamento relacionado a viagens de trabalhadores do setor industrial e comercial, em termos de três grupos de variáveis: participação em atividades, características socioeconômicas e uso do solo. Este trabalho baseia-se na Pesquisa Origem-Destino, realizada na Região Metropolitana de São Paulo (RMSP) em 1997. Foram encontradas relações entre as variáveis consideradas (Árvore de Decisão), e a significância estatística das variáveis independentes (Regressão Linear Múltipla). Foi analisada a influência dos três grupos de variáveis na escolha dos padrões de viagens: (A) Variáveis socioeconômicas (Renda domiciliar, Vale transporte e Posse de automóveis) afetam a sequencia do modo de transporte; (B) Participação em atividades (Estuda e Trabalha) tem um efeito na sequencia dos motivos de viagem; e (C) variáveis de uso do solo (proporção acumulada de empregos por determinado raio a partir dos centroides das zonas de tráfego dos domićlios) influenciam a sequencia de destinos escolhidos, sobretudo para o caso de trabalhadores na indústria. Os diferentes arranjos espaciais das atividades econômicas (comerciais e industriais) na cidade influenciam a viagem dos trabalhadores. Este artigo contribui essencialmente através da proposta de uma variável de uso do solo, proveniente do modelo de oportunidades intervenientes, bem como na apresentação de um método que combina a aplicação conjunta de técnicas de análise multivariada de dados exploratórias e confirmatórias.

Palavras-Chave: comportamento relacionado a viagens, uso do solo, participação em atividades, variáveis socioeconômicas.

*Email: cirapitombo@gmail.com.

\section{Recommended Citation}

Pitombo, C. S., Kawamoto, E. and Sousa, A. J. (2013) Linking activity participation, socioeconomic characteristics, land use and travel patterns: a comparison of industry and commerce sector workers. Journal of Transport Literature, vol. 7, n. 3, pp. 59-86.

- JTL/RELIT is a fully electronic, peer-reviewed, open access, international journal focused on emerging transport markets and published by BPTS - Brazilian Transport Planning Society. Website www.transport-literature.org. ISSN 2238-1031. 


\section{Introduction}

The objective of this work is to find relationships between travel patterns (dependent variable) and the three independent variable groups mentioned before: (A) activity participation; (B) socioeconomic characteristics; and (C) environmental factors (distribution and degree of activities, defined as land use variables) considering groups of individuals characterized as either industry or commerce sector workers.

People generate complex urban travel patterns while engaging in out-of-home activities, which vary based on individual characteristics, household attributes and environmental characteristics. One of the objects of the Activity Based Travel Approach is to investigate the variables that affect travel patterns.

Several authors (Bhat and Singh, 2000; Bowman and Ben-Akiva, 2000; Lu and Pas, 1999; Strathman and Dueker, 1990) suggested that the journeys of individuals can be influenced by three main factors: (A) activity participation, (B) socioeconomic characteristics and (C) environmental factors (urban densities, distances between localities, spatial coverage of the transportation network, and so on).

The idea that socioeconomic characteristics and activity participation can influence travel behavior has been studied previously (Arentze et al., 2000; Balasubramaniam and Goulias, 1999; Golob and Mcnally, 1997; Bhat and Koppelman, 1991; Kwan, 2000). The conclusions in the literature suggest that personal travel can be determined by gender, car ownership (Strambi et al., 2004; Mcguckin and Murakami, 1999), the role of the person in the family, household task allocation (Simma and Axhausen, 2001; Srinivasan and Athuru, 2005) and activity participation (classified as subsistence, leisure, medical, shopping, and so on).

However, socioeconomic characteristics and individual activities are only part of the set of variables that can allow for the prediction of travel behavior. Not only car ownership, but also the distribution of activities in the urban environment and accessibility to opportunities affect modal choice and destination choice. The locations where people live or work exert strong influence over urban trips. 
Environmental factors, such as road infrastructure networking, urban configuration, localization of activity centers in the cities, density and land use influence travel behavior. In the present work, environmental factors (land use variables) are defined as the spatial distribution and degree of activity for each economic sector (industry and commerce).

The assumption that land use policy can influence travel behavior follows from the correlation between the variables considered. Diverse works confirm that land use (characterized by urban densities, cities being compact or spread-out, the distribution of economic activities in urban environments and the presence of Traffic Zones with mixing activities) is strongly related to travel behavior, especially modal choice (Cervero and Radisch, 1996: Ewing, 1995; Kitamura et al., 1997). The proposal of the land use variables is one contribution described in this paper. Besides, we can note in this work, the influence of this variables group on travel behavior, especially considering workers in industry sectors.

Six steps were performed and are described in the following sections. Section 1 describes the main characteristics of the study area and the data preprocessing; Section 2 presents the representation of independent variables: categorical and numeric; Section 3 designates the representation of the categorical dependent variable; Section 4 - Part 1 (Exploratory Analysis - Classification and Regression Tree (CART) application) - was used to find a priori unknown relations; Section 5 - Part 2 (Confirmatory Analysis - Multiple Linear Regression (MLR) application) - was applied to verify the statistical significance of the variables and to corroborate the previously results obtained through CART application; the conclusions finally are described in the last section. 


\section{Study area: São Paulo Metropolitan Area}

São Paulo is the largest Brazilian metropolitan area, with a population of over 17 million distributed over 39 counties, including São Paulo city. Analysis was based on data obtained during the origin-destination home-interview survey carried out by METRÔ-SP in the São Paulo Metropolitan Area (SPMA) in 1997.

The region was divided into seven sub-regions and 389 Traffic Zones (TZs). The original sample contains 98,780 individuals and 28,278 households representing $0.61 \%$ of the total number of the households.

To analyze the behaviors of both industry and commerce sector workers and consider the hypothesis that the spatial distribution of economic activities in the urban environment affects the travel of individuals, two different analyses were performed:

(1) Analysis of the spatial distribution of industrial and commercial jobs in the study area and

(2) analysis of the main changes in the job market of the SPMA, considering the two economic sectors.

Both analyses are presented in the next two sub-sections. After that, the data treatment and the resulting sub-samples are described.

\subsection{The spatial distribution of industrial and commercial jobs (SPMA)}

There are concentrations of industry sector jobs (Figure 1) in some specific regions: (1) The TZs of Pimentas, Rodovia Presidente Dutra and Guarulhos; (2) the ABCD region; and (3) the counties of Barueri and Osasco. The SPMA basically has three main industrial centers, although there is some concentration of industrial jobs in the central TZs. 


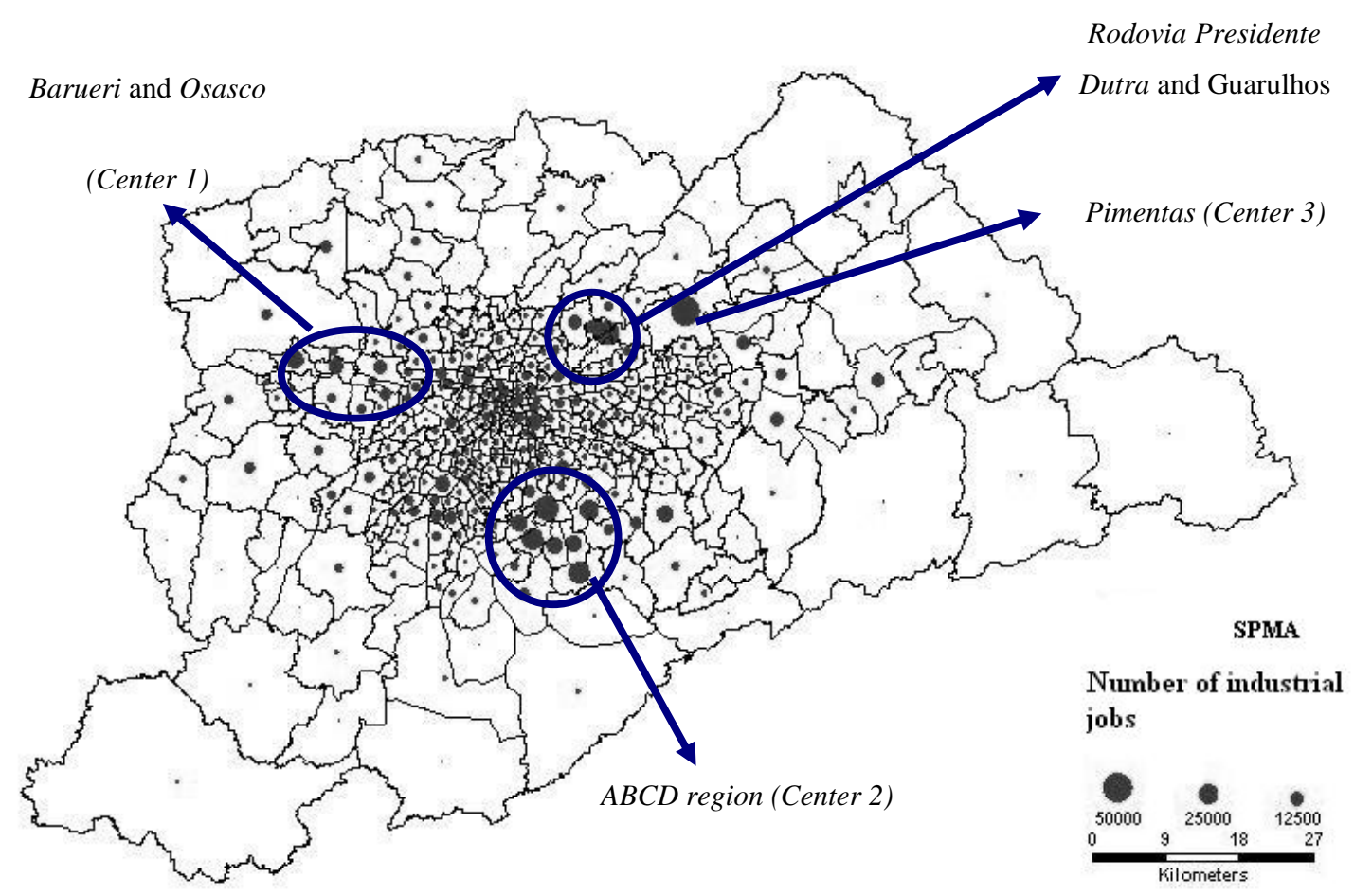

Figure 1 - Spatial distribution of industrial jobs. Source: METRÔ-SP

There is a strong concentration of commercial jobs (Figure 2) in the central region. There are also a great number of commercial jobs in $A B C D$ region and four main centers: (1) The TZs of Itaquaquecetuba, Suzano and Mogi das Cruzes; (2) Guarulhos and Vila Galvão; (3) Carapicuíba, Jardim Veloso and Santo Antonio; and (4) Jardim São Luis, Centro Empresarial and Vila Santa Catarina. Commercial activities are relatively dispersed in the SPMA, with six main centers of commercial job concentration.

Industrial jobs are concentrated in three main centers located within the study area, while commercial jobs are scattered over the entire region. Thus, the economic sectors were analyzed separately to obtain more appropriate results.

The purpose was to reveal the possible influence of land use comparing two specific cases (industry and commerce sector workers). It was anticipated that land use variables would exert a greater influence in the case of industry sector workers due the concentration of industrial jobs in the determined traffic zones.

This analysis can indicate future changes in the travel of individuals, as there is an increase of jobs in the tertiary sector and a decrease in industrial jobs (sub-section 1.2). 


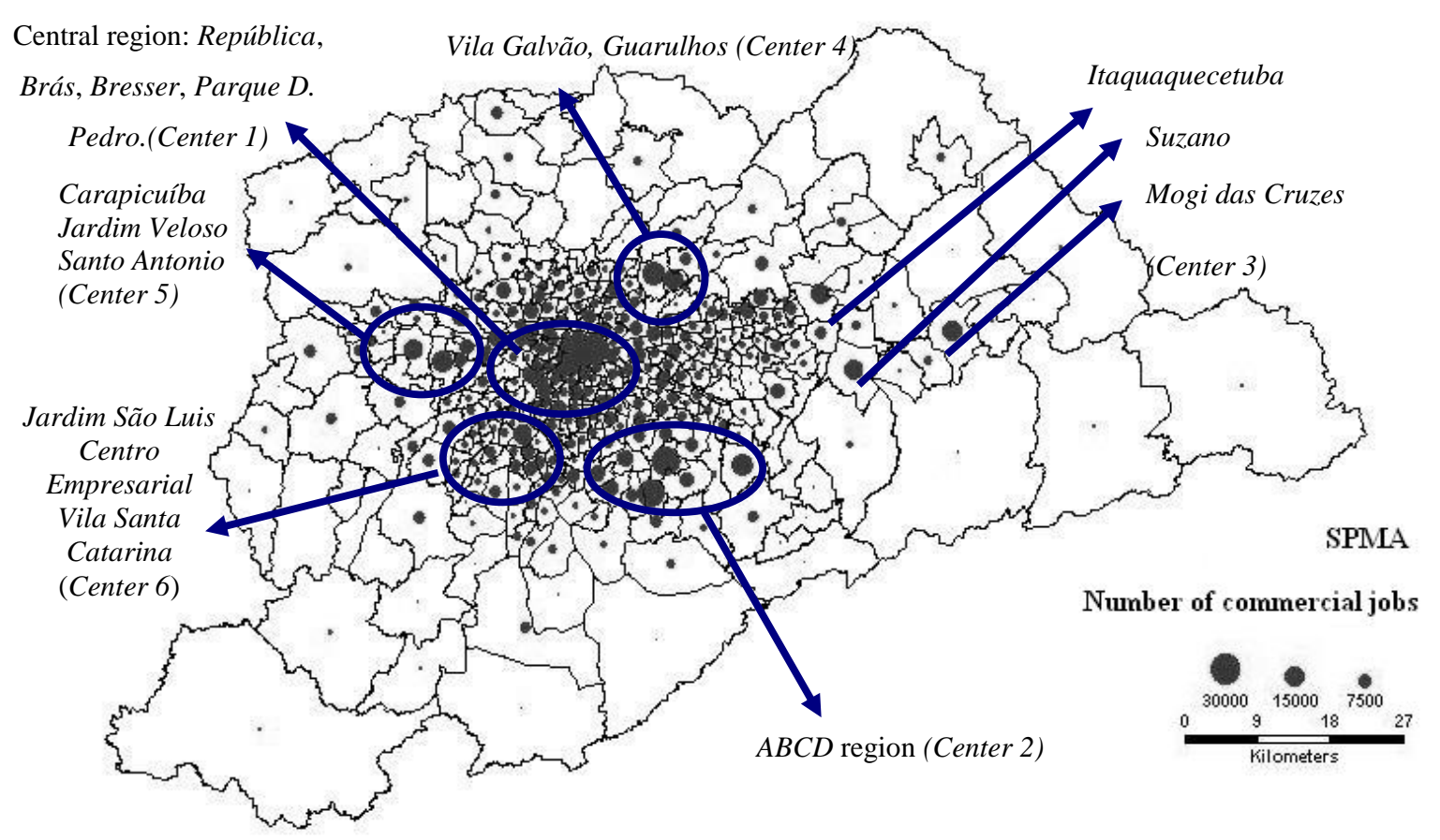

Figure 2 - Spatial distribution of commercial jobs. Source: METRÔ-SP

\subsection{Changes in the job market of the SPMA}

Over the past 20 years, the SPMA has undergone significant socioeconomic and demographic changes, which can be seen in the analysis of the data collected for the Instituto Brasileiro de Geografia e Estatística (IBGE) and Fundação Estadual de Análise de Dados de São Paulo (SEADE).

There were considerable changes in the economic activities of the region, mainly in the 1980s. These include:

(1) the reduction of industrial jobs;

(2) the expansion and consolidation of service and commerce activities;

(3) the deterioration of the job market; and

(4) the increase in unemployment taxes and the number of autonomous workers.

As indicated by the IBGE information, the SPMA had an unemployment tax of $3.9 \%$ in 1980 , $5.8 \%$ in 1990 and $8.4 \%$ in the first semester of 2002. The participation of autonomous 
workers in the job market increased from $19 \%$ to $29 \%$, and the participation of the employees fell from 58\% to 48\% between 1991 and 2002.

The advance of technology is pointed to as a main reason for the elimination of industrial jobs. New technologies such as informatics, communications and robotics caused the disappearance of some occupational categories. Moreover, in the 1980s and 1990s, a widespread process of industrial decentralization occurred in the state of São Paulo. A great number of industrial establishments moved from the capital (and its periphery) to other cities, promoting the increase of urban medium-sized centers and generating new transformations in the SPMA.

\subsection{Data preprocessing}

In this stage, incomplete data or those that were not relevant to the objectives were eliminated. The initial sample was composed of the records for 98,780 individuals, aggregate data of the home traffic zones of each individual and the Euclidean distances of all the trips. The following individuals were selected for analysis:

- $\quad$ individuals who made 2, 3 or 4 trips on the day prior to survey;

- individuals who made home-based tour; and

- individuals that work in the industry or commerce sectors.

Finally, considering the differences in the geographic distribution of jobs in the SPMA and the research hypotheses that the different spatial distributions of economic activities (commercial and industrial) in the urban environment influence the travel of commerce or industry sector workers, two sub-samples were identified: (a) industry sector workers and (b) commerce sector workers. 


\section{Independent variables representation}

The independent variables (categorical or numerical) used in this work belong to the three main variables groups: (A) socioeconomic characteristics, (B) activity participation and (C) land use characteristics.

The independent variables selected here are related to travel patterns. The variables of the first and the second groups were chosen based on the literature and data availability.

(A) Socioeconomic variables: Household income (HI); Car ownership (AUT); Position of the individual in the family (PF) (1: Head; 2: Spouse; 3: Child; 4: Relative; 5: House servant; 6: Visitor); Family size (FS); Level of education (LE); Gender; Age; Transit pass ownership (TP).

(B) Participation in subsistence activities: Work (W) (1: Employee; 2: Autonomous; 3: Unemployed); Study (S) (1: Don’t study; 2: Elementary school; 3: High school and college; 4: Other courses).

The third variable group is proposed based on the principles of the intervening opportunities model (Schneider, 1959). It will be discussed in detail in the following subsection.

\subsection{Land use variables}

For elaboration of the land use variables, the intervening model principle was adopted. This principle assumes that, in the urban area, all trips are as short as possible. Individuals accomplish long trips only to reach the next acceptable destination, where their purpose is satisfied. In this work, land use variables are represented in terms of degree of "accumulated opportunities" for the distance buffer.

In this work, the term "opportunities" refers to the job supply in the economic sector. Considering the two sub-samples, "opportunities" represents "the proportion (\%) of the total jobs in the industry sector" (for the case of industrial workers) and "the proportion (\%) of the total jobs in the commerce sector" (for the case of commercial workers). These measurements were collected for various distance buffers starting from the home TZ centroid up to $5,10 \mathrm{~km}$, 15 and $20 \mathrm{~km}$, which were used to generate "accumulated opportunities" measurements. 
Figure $3(a, b$ and $c)$ shows the land use variables. The zone of origin is the shaded area " $A$ ". At stage (a), the values of the "opportunities" are represented in (\%) for each zone together with straight-line distances from the centroid of "A". In (b), the "accumulated opportunities" for each of the four distance buffers are shown. Finally, at stage (c), the land use variables from TZ "A" are illustrated.

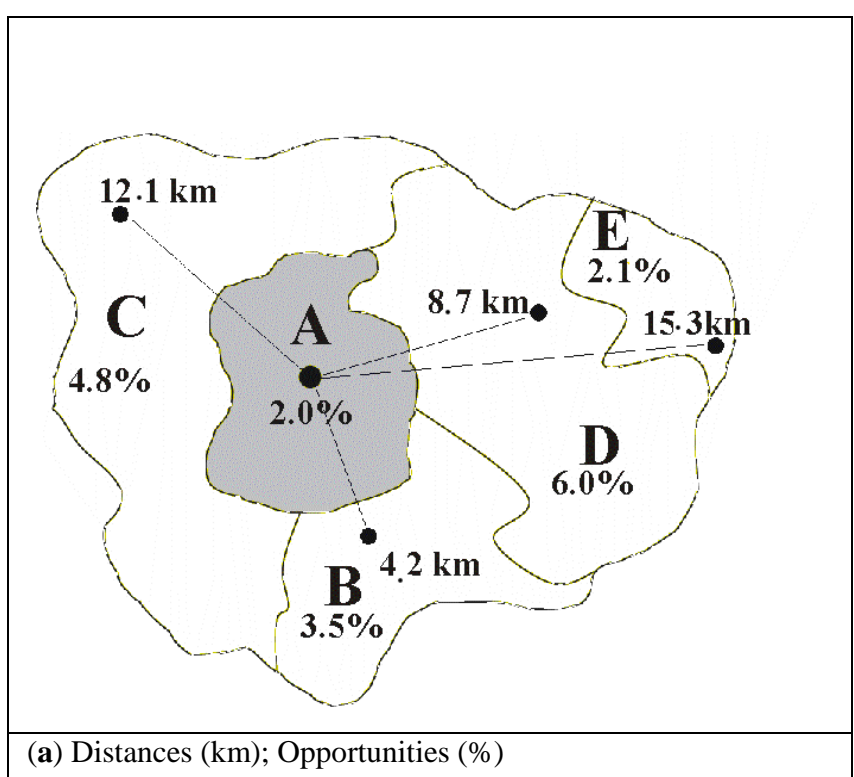

\begin{tabular}{|c|c|c|c|c|c|c}
\hline \multirow{2}{*}{ TZ } & \multirow{2}{*}{$\begin{array}{c}\text { Distances } \\
\text { between } \\
\text { "A"centroid }\end{array}$} & $\begin{array}{c}\text { Opportuni- } \\
\text { ty(\%) }\end{array}$ & \multicolumn{4}{|c}{ Accumulated Opportunities } \\
\cline { 4 - 7 } & $\begin{array}{c}\text { Until } \\
\text { and others Tzs }\end{array}$ & Until & Until & Until \\
& centroids & $\mathrm{ZT}$ & 5 & 10 & 15 & 20 \\
& $\mathbf{k m}$ & $\mathrm{km}$ & $\mathrm{km}$ & $\mathrm{km}$ \\
\hline $\mathrm{A}$ & $0.0 \mathrm{~km}$ & 2.0 & 2.0 & 2.0 & 2.0 & 2.0 \\
$\mathrm{~B}$ & $4.2 \mathrm{~km}$ & 3.5 & 3.5 & 3.5 & 3.5 & 3.5 \\
$\mathrm{C}$ & $12.1 \mathrm{~km}$ & 4.8 & & & 4.8 & 4.8 \\
$\mathrm{D}$ & $8.7 \mathrm{~km}$ & 6.0 & & 6.0 & 6.0 & 6.0 \\
$\mathrm{E}$ & $15.3 \mathrm{~km}$ & 2.1 & & & & 2.1 \\
\hline
\end{tabular}

(b) Accumulated Opportunities calculation 


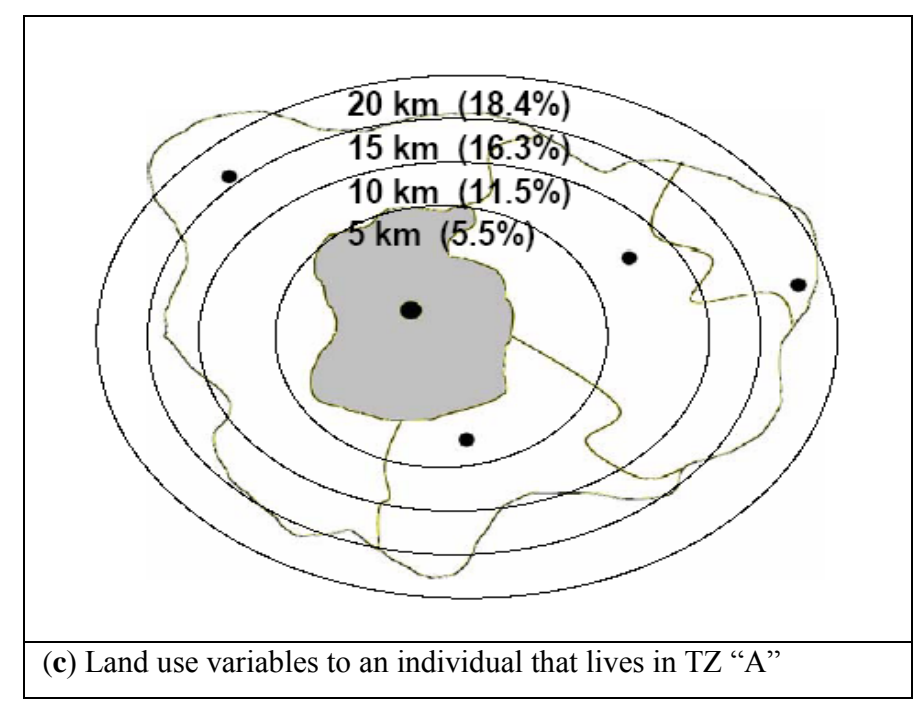

Figure 3 (a,b,c) - Land use variables

The land use variable set defined here represents the distribution and degree of activities in the urban environment (accumulated opportunities in the industry sector up to $5 \mathrm{~km}$ from the home TZ, accumulated opportunities in the industry sector up to $10 \mathrm{~km}$ from the home TZ, and so on).

\section{Coding the categories of the dependent variable}

In this study, the trip-linking representation was based on activity sequence, travel mode and destinations chosen for the individuals in the period of one day. The dependent variable coding follows the scheme below.

(a) Activity sequence

(b) Travel mode sequence

(c) Sequence of trip destination

(d) Final Travel Pattern - combination of the previous stages

The travel attributes (activities, travel mode and destinations) were grouped and represented by letters and numbers, as shown in Table 1 . The 128 categories of dependent variables are represented by alphanumeric codes that correspond to the sequence of the adopted travel 
attributes. As mentioned before, it was assumed that the individual's residence was the initial origin and final destination for those who took two, three or four trips.

Table 1 - Travel Patterns Representation

\begin{tabular}{|c|c|c|c|}
\hline \multirow{2}{*}{\multicolumn{2}{|c|}{$\begin{array}{c}\text { Step A } \\
\text { Activity Sequence }\end{array}$}} & \multicolumn{2}{|r|}{ Step B } \\
\hline & & \multicolumn{2}{|c|}{ Travel Mode Sequence } \\
\hline \multicolumn{2}{|r|}{ Letters } & \multicolumn{2}{|r|}{ Letters } \\
\hline $\mathrm{H}$ & Home & $\mathrm{P}$ & Private \\
\hline $\mathrm{W}$ & Work & $\mathrm{T}$ & Transit \\
\hline $\mathrm{S}$ & School & $\mathrm{N}$ & Non-motorized \\
\hline A & Other Activities & & \\
\hline \multicolumn{4}{|c|}{ Step C } \\
\hline \multicolumn{4}{|c|}{ Destination (distance to the home Traffic Zone (TZ) centroid) } \\
\hline \multicolumn{4}{|c|}{ Numbers } \\
\hline 1 & \multicolumn{3}{|c|}{ until 5 kilometers from home TZ centroid } \\
\hline 2 & \multicolumn{3}{|c|}{ 5-10 kilometers from home $\mathrm{TZ}$ centroid } \\
\hline 3 & \multicolumn{3}{|c|}{ 10-15 kilometers from home $\mathrm{TZ}$ centroid } \\
\hline 4 & \multicolumn{3}{|c|}{ above 15 kilometers from home $\mathrm{TZ}$ centroid } \\
\hline
\end{tabular}

In the first step, the travel patterns were represented by a sequence of letters $(\mathrm{H}, \mathrm{W}, \mathrm{S}$ and $\mathrm{A})$ indicating the sequence of activities performed by the individuals during the day (HSH: home - school - home). In the subsequent stage, the letters $(\mathrm{P}, \mathrm{T}$ and $\mathrm{N})$ indicate the travel mode sequence used (NN: Non-motorized - Non-motorized).

In the third step, the sequence of destinations was characterized by numbers (1, 2, 3 and 4). Each one of the numbers represents distance buffers starting from the home zone centroid (Table 1). The first and last numbers always represent the initial and final destination, the individual's home (represented by number 1). For example, pattern 141 indicates the accomplishment of two trips: (first trip) starts at home (number 1) and continues to a destination located more than $15 \mathrm{~km}$ away (number 4); (second trip) denotes the return from destination (4) to the home (number 1).

According to the coding defined in the previous stages, the final travel patterns are represented by three sets of characters: The first set refers to the activity sequence (e.g., HWAH), the second set corresponds to the travel mode sequence (TTT, for example) and the final set describes the destination sequence (e.g., 1121). The resulting travel pattern HWAH TTT 1121, for example, is illustrated in Figure 4. 


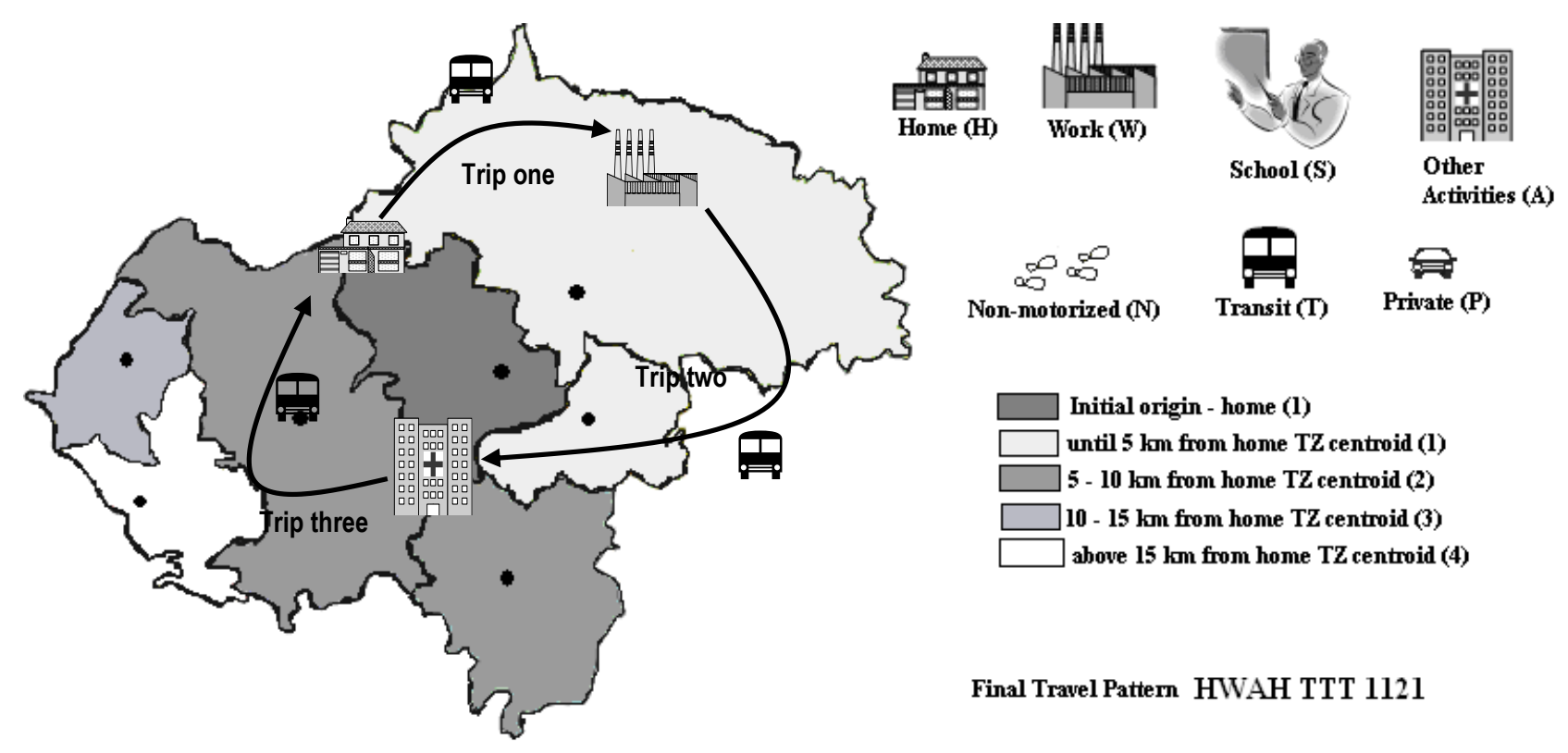

Figure 4 - Travel patterns (activity, travel mode and destination)

After representing the dependent variable categories, the individuals with less frequent travel patterns were eliminated in each one of the sub-samples due to the software (S-PLUS 6.1) limitation of 128 categories of dependent variable. Finally, two sub-samples were obtained: (a) industrial workers - 4,102 individuals; and (b) commercial employees - 6,043 individuals.

\section{Exploratory analysis}

The CART (Classification and Regression Tree) algorithm was used in the current research. This technique allows successive division of a population into binary splits. The resultant subgroups are homogeneous with respect to the dependent variable, yielding a hierarchical tree of decision rules useful for prediction or classification (Breiman et al., 1984).

CART is a segmentation modeling technique that satisfies the following properties:

(a) the hierarchy is called tree and each segment is a node;

(b) the root node contains the complete database;

(c) the root node is divided sequentially, generating child nodes; 
(d) when no further data subdivision is possible, the final subgroups are considered terminal nodes or leaves;

(e) for construction of the CART three main elements should be determined: a set of questions delimiting data division, a criterion for evaluation of the best division and a rule for termination of further subdivisions (stop-splitting rule); and

(f) each division depends on the value of a unique independent variable. Thus, amongst the set of independent variables, the one that gives the best split is chosen (greatest segregation of the data). The procedure continues until no significant splits remain. In this form, multicollinearity does not cause any problems for the algorithm, therefore, the independent variables are analyzed separately (Piramuthu, 2008).

Using this technique, two trees were generated from the final sub-samples of industrial and commercial workers, 128 categories of dependent variable (travel patterns) and numerical and categorical independent variables (three variable sets mentioned in the work). The trees, illustrated in Figures 5-6, were generated using at least 50 observations for each leaf node, using 0.15 for global node deviance (stop-splitting rule) and resulting in 10 leaves for industry sector workers and 8 leaves for commerce sector workers.

The figures display the CART with the two most frequent travel patterns at each terminal node (leaves) obtained using SPLUS 6.1. The figures show stages of the construction of the trees, representing the influence of each variable in travel pattern choices in each sub-sample and differences of travel behavior between industrial and commercial workers. The subsection below describes the influence of each independent variable selected on the travel behavior of industry and commerce sector workers.

\subsection{Independent variable influence: The CART algorithm}

The first independent variable selected in the industry sector worker sample was "car ownership" (AUT). The data were segregated into two branches: (1) branch 1 - AUT=0 (terminal nodes $11 ; 20 ; 21 ; 8$ and 9); and (2) branch 2 - AUT $\geq 1$ (terminal nodes 7; 27; 53; 52 and 12). 
In analysis of the commerce sector workers sample, "car ownership" was selected for the second split: (1) AUT=0 (terminal nodes 21; 20 and 8); and (2) AUT $\geq 1$ (terminal nodes 19; 18 and 10).

Figure 5 (a) shows the "car ownership" influence. In both samples, individuals that had cars at the household used an automobile in travel sequences most frequently. According to the terminal nodes and the two predominant travel patterns, people that do not have cars at the household predominantly use transit or non-motorized travel modes (TT, NN, NNNN, NNN). There is a predominance of car usage in individuals who have at least one car at the household (PP, PPP).

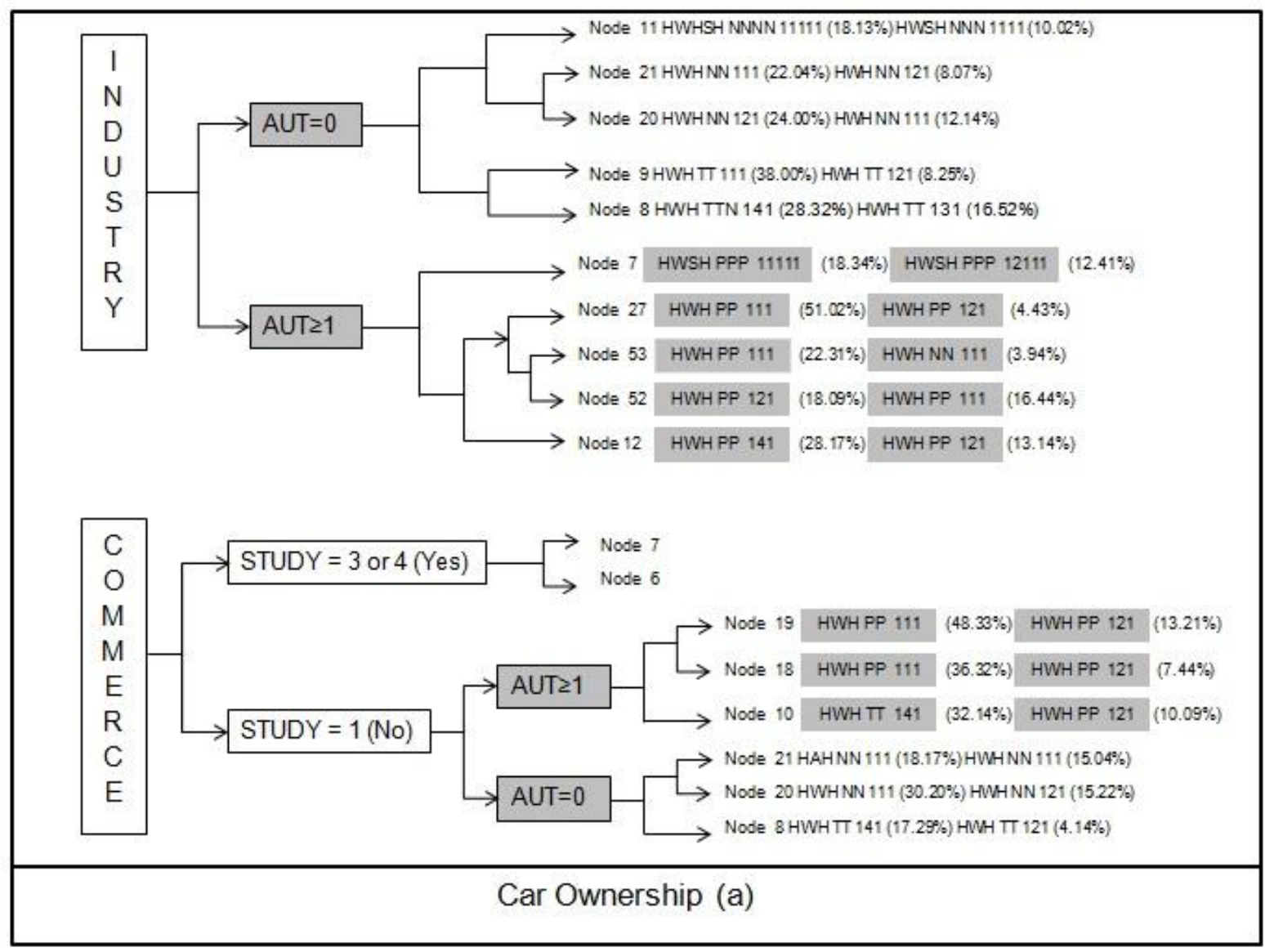

Figure 5 - CART construction (a) Car Ownership influence

As seen in Figure 5 (b), the participation of individuals in scholarly activities (variable "study") possibly influences the activity sequence in both cases (industry and commerce sector workers). Those individuals that study (and also are workers) perform different activity sequences. This fact can be observed through terminal nodes 11 and 7 (CART for industry 
sector workers) and nodes 7 and 6 (CART for commerce sector workers). These groups of people predominantly perform activity sequences related to school and work HWSH; HWHSH.

The individuals who are not studying (terminal nodes 21, 20, 27, 53, 52 and 12 - Industry; terminal nodes $19,18,10,21,20$ and 8 -Commerce) more frequently perform work-related activity sequences only (HWH).

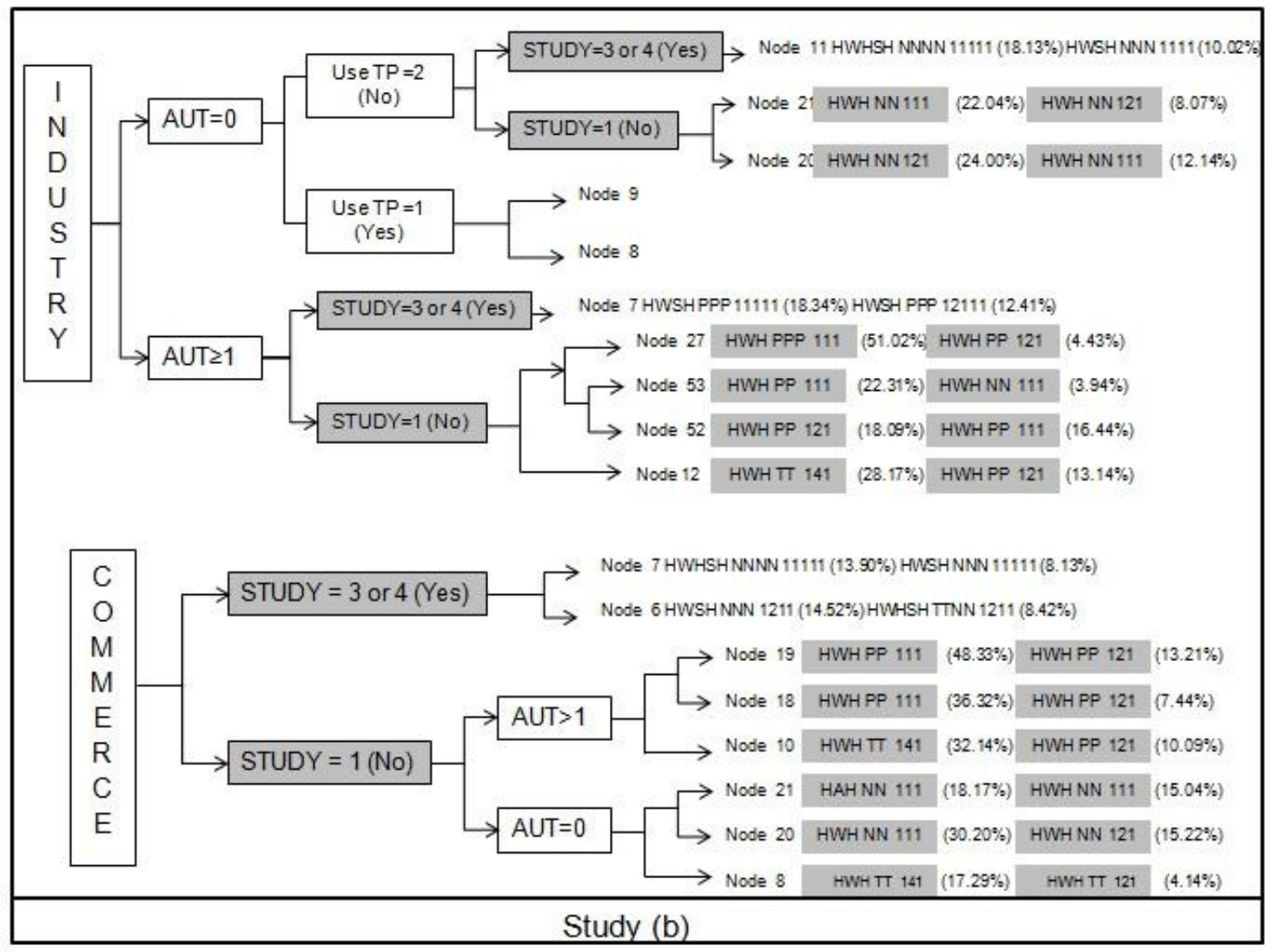

Figure 5 - CART construction (b) Study influence

Among groups of individuals owning a transit pass (variable "Transit Pass Ownership"), there is a predominance of transit usage TT (Figure 5 (c) - terminal nodes 9, 8 and 12 Industry; terminal nodes 10 and 8 - Commerce). Those people who do not own a transit pass (terminal nodes 11, 21, 20 27, 53 and 52 - Industry; terminal node 19, 18, 21 and 20 Commerce) are more inclined towards the particular or non-motorized travel modes $(\mathrm{NN}$, NNN or PP).

Specific cases were observed, in both samples, of individuals who prefer to use transit for long trips (141) even if there is a car at their household. In these cases, taking into account the 
distance to be covered (exceeding $15 \mathrm{~km}$ ), travel costs will probably be lower than with car usage (fixed tariff of transit - specifically for the SPMA). These cases are shown in terminal nodes 12 (industry) and 10 (commerce).

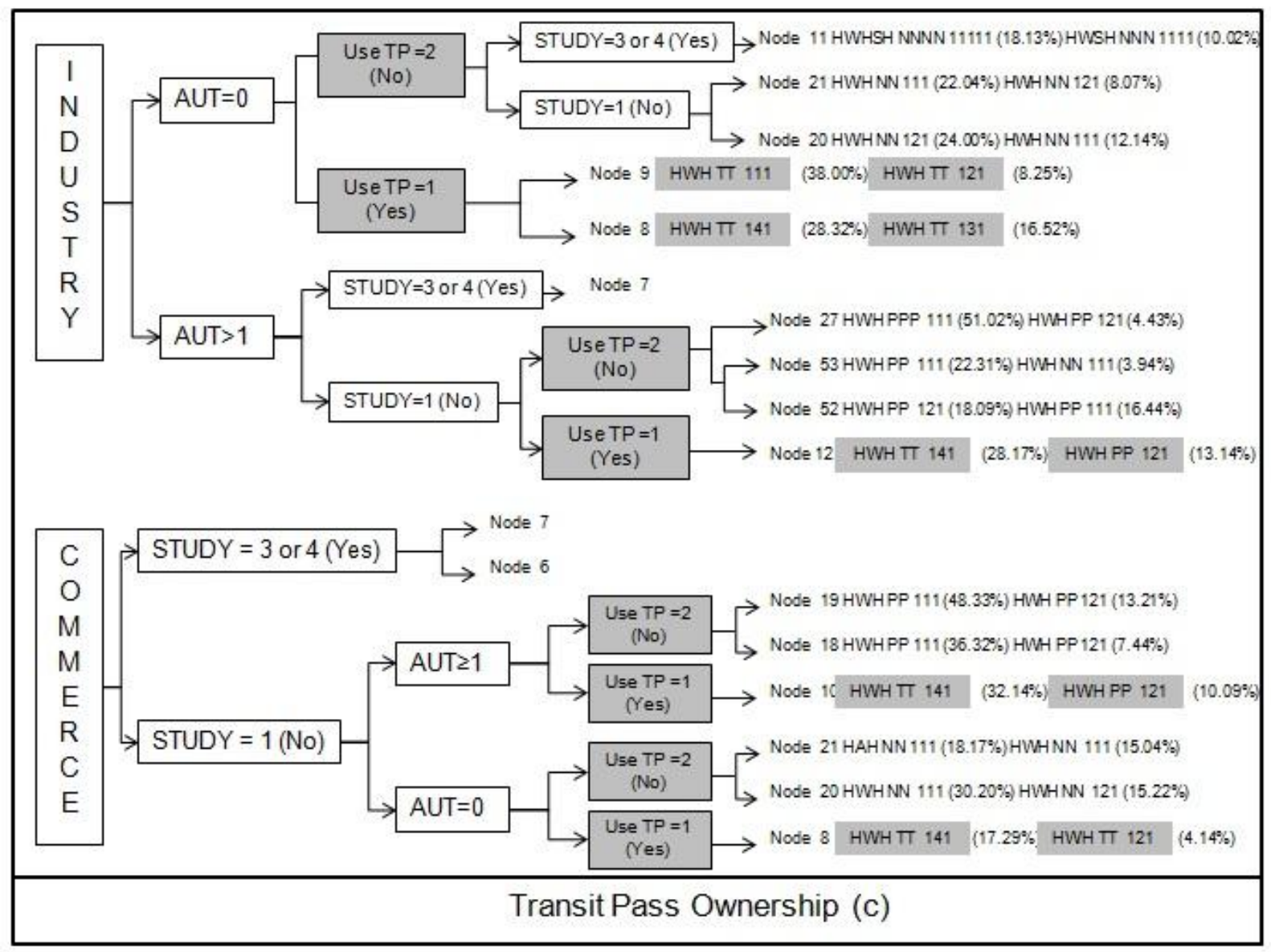

Figure 5 - CART construction (c) Transit Pass Ownership influence

Individuals that have higher incomes frequently tend to use cars in the travel mode sequence. For industrial workers, for example, the majority of individuals with a Household Income greater than or equal to $\mathrm{R} \$ 2970^{1}$ (terminal node 27) use an automobile - HWH PP 111 $(51.02 \%)$ and HWH PP 121 (4.43\%). For commercial workers, a great number of individuals with a Household Income greater than or equal to $\mathrm{R} \$ 2260^{2}$ (terminal node 19) also use cars in the travel mode sequences HWH PP 111 (48.33\%) and HWH PP 121 (13.21\%) - Figure 6 (a).

\footnotetext{
${ }^{1} 1 \mathrm{R} \$($ Real Brazilian $)=0.50$ American Dollar; $2,970 \mathrm{R} \$=1,485 \mathrm{U} \$$

$2,260 \mathrm{R} \$=1,130 \mathrm{U} \$$
} 


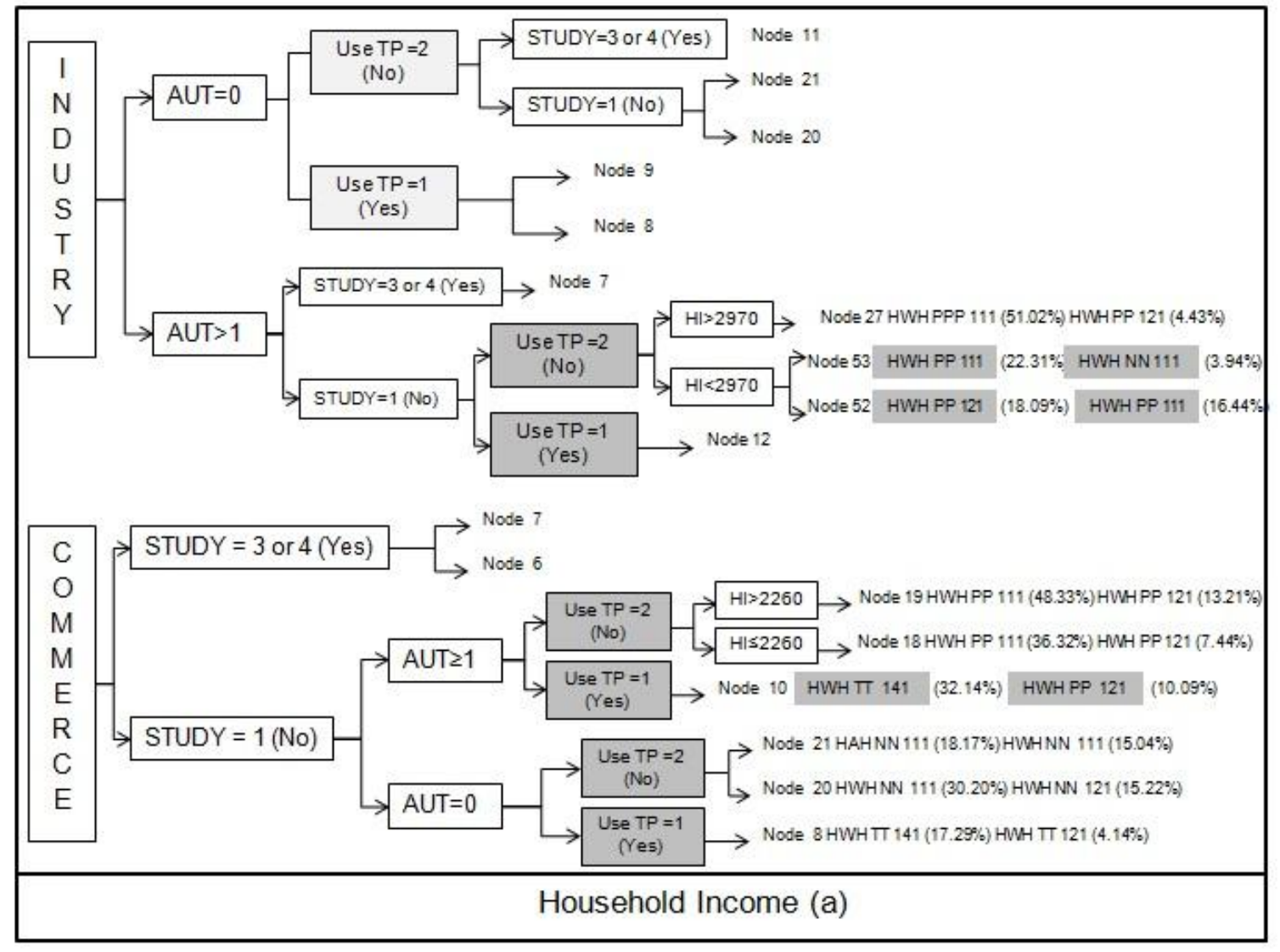

Figure 6 - CART construction (a) Household Income influence.

For the industrial workers (Figure 6 (b)), land use variables (accumulated opportunities in the industry sector until $5 \mathrm{~km}$ from the Home TZ (5 IND km); accumulated opportunities in the industry sector until $10 \mathrm{~km}$ from the Home TZ (10 IND km); accumulated opportunities in the industry sector until $15 \mathrm{~km}$ from the Home TZ (15 IND km)) exert significant influences on the sequences of destinations.

In the case of industrial workers especially, individuals that live in traffic zones with few accumulated job opportunities in their neighborhoods (IND $5 \mathrm{~km}<3.22 \%$, e.g., terminal node 8) tend to carry out longer trips related to work (HWH TT 141), see Figure 6 (b).

It is noted that only one of the land use variables in the sample of commercial workers was selected (COM $5 \mathrm{~km}$ - Figure 6 (b)). In this case, the land use variable does not intervene predominantly in destination sequence choice. This result is due to the geographic distribution of commercial jobs. Commercial jobs are sufficiently dispersed, and there are no concentrations demarcated as in the case of the industry sector jobs. 
Moreover, commercial workers more frequently perform short trips (111), which can be explained on the basis of the geographic dispersion of commercial activities in the SPMA. Individuals working in the commerce sector probably live near their work locations.

For commercial workers, the variable "Work" (Figure 6 (c)) influences the choice of the trip purpose sequence. This variable is important due to sample characteristics; there is greater number of autonomous workers in the commerce sector.

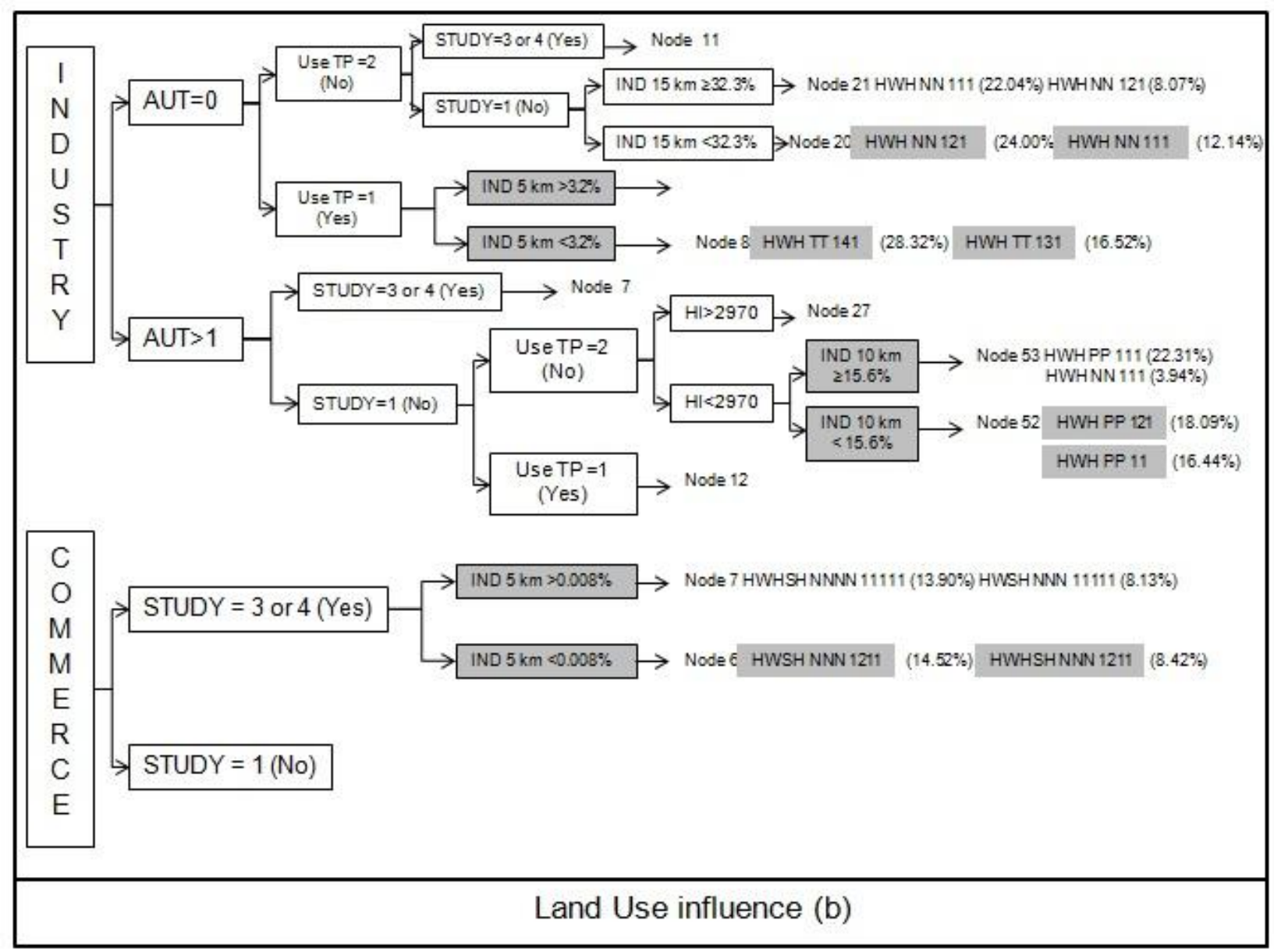

Figure 6 - CART construction (b) Land Use influence

The individuals that were selected in terminal nodes 20 and 21 possess some similar characteristics and can be clearly distinguished for the independent variable "Work". The individuals that form node 20 are employees, while those who are part of node 21 are autonomous workers. Members of the autonomous group generally do not have a need to carry out daily trips related to work and can perform sequences unrelated to work activities. There is a prevalence of the HAH sequence, for example, in the autonomous group. 
In the exploratory stage of this work, results obtained the CART algorithms were analyzed. The influences of some independent variables on trip sequences (activities, travel modes or destinations) were verified. The important influence of the land use variable set in the industrial worker sample was noted. This fact is accounted for by the geographic concentration of jobs in the industry sector in the SPMA.

Considering public policy implications, we could note that is probably possible to change work related trips choices, modifying the spatial arrangement of activities in the industrial and tertiary sectors.

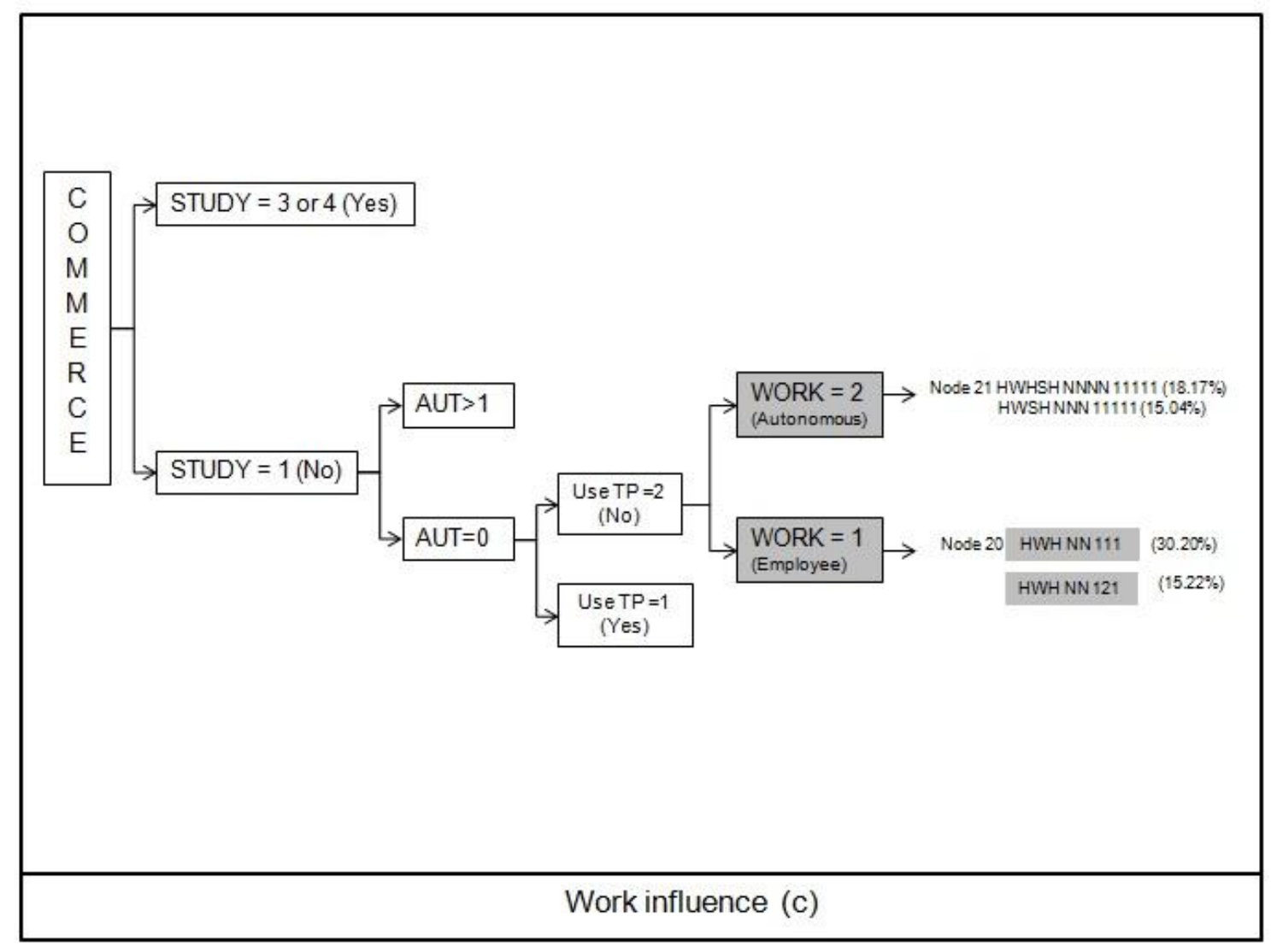

Figure 6 - CART construction (c) Work influence

The next stage of the study, Multiple Linear Regression (MLR), aimed to corroborate initial conclusions and gain statistical insights. In the confirmatory stage, the parameters used to prove the contribution of the independent variables in the accomplishment of travel patterns were estimated. 


\section{Confirmatory analysis}

In this research, the Multiple Linear Regression (MLR) application was associated with CART application. In this confirmatory stage the following steps were accomplished:

(1) Discretization of independent variables; (2) representation of dependent variable;

(3) Correlation analysis for the independent variables; and (4) achievement of linear models and discussions.

The categorization of independent variables was the first step. Each continuous variable was divided into two classes (dummy variables) to reduce the eventual non-linearity between independent and dependent variables. The corresponding values for the classes of the dummy variables were obtained through CART application. Thus, for example, the continuous variable IND $5 \mathrm{~km}$ became a dummy variable with the following values: (a) 5 IND $\mathrm{km}<3.2 \%$ (0); (b) 5 IND $\mathrm{km}>3.2 \%$ (1). This process was repeated for all independent variables selected by the CART application and the values used for the data split.

The following example illustrates the representation of dependent variables:

(1) The individual 1 belonging to the industry sector workers sub-sample is considered;

(2) During the CART construction, individual 1 was classified in terminal node 8;

(3) People classified in terminal node 8 have a probability of 0.22 of carrying out the travel pattern HWH TT 121, for example; and

(4) This probability is the value of the dependent variable "y", corresponding to individual 1.

In this work the probability of the occurrence of ten travel patterns was considered for each individual of the two sub-samples. The ten travel patterns considered were: HWH TT 141, HWH TT 131, HWH TT 121, HWH TT 111, HWH PP 141, HWH PP 131, HWH PP 121, HWH PP 111, HWH NN 121 and HWH NN 111. Thus, ten linear models for each sub-sample were obtained (total of 20), where the dependent variables are the probabilities of the occurrence of each one of the ten adopted travel patterns for individuals. 
An analysis of the correlations between all variables, including the independent variables (dummy) and the dependent variables (numerical 0 to 1 ), was performed. If two independent variables were detected to be highly correlated, the one that was less correlated with the dependent variable was discarded. Table 2 shows each of the twenty linear models, the coefficient values associated with each of the independent variables (parameters) and $t$ statistics and $\mathrm{R}^{2}$ values. Table 3 describes the independent dummy variables.

All twenty models obtained were considered acceptable, with values of $\mathrm{R}^{2}$ varying from 0.570 (model HWH PP 141 of the sample of commerce sector workers) to 0.893 (model HWH TT 121 of the sample of industry sector workers).

All independent variables were significant, with relatively high values of t-statistics. Moreover, all the coefficient values (parameters) obtained were coherent. In the next subsection, the contributions of each variable for the accomplishment of the ten travel patterns for the two sub-samples will be described.

\subsection{Independent variable influence: The MLR models}

Having at least one car in the household (value one for the variable "car ownership"- AUT), results in a negative contribution to the accomplishment of travel patterns associated with transit (TT) or non-motorized (NN or NNNN) travel mode sequences in both sub-samples. HWH TT 141 (industry (-0.006); commerce (-0.002)); HWH TT 131 (industry (-0.019); commerce (-0.029)); HWH TT 121 (industry (-0.038); commerce (-0.039)); HWH TT 111 (industry (-0.084); commerce (-0.059)); HWH NN 111 (industry (-0.133); commerce (-0.087)) and HWHSH NNNN 11111(industry (-0.024); commerce (-0.034)). 
Table 2 - Results of MLR Application

\begin{tabular}{|c|c|c|c|c|c|c|c|c|c|c|c|c|c|c|}
\hline \multicolumn{4}{|c|}{ Linear Models } & Intercept & AUT & TP & $\mathrm{HI}$ & Study & Work & IND $5 \mathrm{~km}$ & IND $10 \mathrm{~km}$ & IND $15 \mathrm{~km}$ & COM $5 \mathrm{~km}$ & $\mathrm{R}^{2}$ \\
\hline \multirow{17}{*}{ 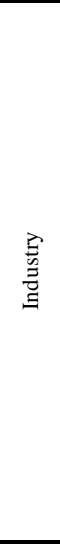 } & \multirow{2}{*}{1} & \multirow{2}{*}{ HWH TT 141} & B & 0.261 & -0.006 & -0.109 & -0.025 & -0.048 & & -0.101 & & & & \multirow{2}{*}{0.725} \\
\hline & & & $\mathrm{t}$ & 145.85 & -9.81 & -56.56 & -9.09 & -16.92 & & -54.71 & & & & \\
\hline & \multirow{2}{*}{2} & \multirow{2}{*}{ HWH TT 131} & $B$ & 0.15 & -0.019 & -0.089 & -0.03 & -0.033 & & & -0.046 & & & \multirow{2}{*}{0.834} \\
\hline & & & $\mathrm{t}$ & 254.43 & -9.98 & -106.77 & -24.16 & -34.29 & & & -43.76 & & & \\
\hline & \multirow{2}{*}{3} & \multirow{2}{*}{ HWH TT 121} & B & 0.227 & -0.038 & -0.099 & -0.055 & -0.061 & & & & -0.004 & & \multirow{2}{*}{0.893} \\
\hline & & & $\mathrm{t}$ & 315.23 & -47.78 & -124.79 & -48.2 & -52.31 & & & & -5.52 & & \\
\hline & \multirow{2}{*}{4} & \multirow{2}{*}{ HWH TT 111} & B & 0.207 & -0.084 & -0.09 & -0.058 & -0.033 & & 0.066 & & & & \multirow{2}{*}{0.718} \\
\hline & & & $\mathrm{t}$ & 140.44 & -52.62 & -56.5 & -22.33 & -14.06 & & 37.03 & & & & \\
\hline & \multirow{2}{*}{5} & \multirow{2}{*}{ HWH PP 141} & $\bar{B}$ & & 0.047 & 0.024 & 0.099 & -0.043 & & -0.011 & & & & \multirow{2}{*}{0.784} \\
\hline & & & $\mathrm{t}$ & & 50.86 & 26.38 & 71.000 & -31.55 & & -12.61 & & & & \\
\hline & \multirow{2}{*}{6} & \multirow{2}{*}{ HWH PP 131} & B & -0.008 & 0.053 & 0.019 & 0.039 & -0.025 & & & 0.008 & & & \multirow{2}{*}{0.839} \\
\hline & & & $\mathrm{t}$ & -19.86 & 94.71 & 41.41 & 30.91 & -37.43 & & & 18.88 & & & \\
\hline & \multirow{2}{*}{7} & HWH PP 121 & B & -0.005 & 0.068 & 0.027 & 0.031 & -0.045 & & & & & & \\
\hline & & НWHРP I21 & $\mathrm{t}$ & -8.0 & 94.27 & 37.17 & 22.000 & -41.88 & & & & & & 0.868 \\
\hline & 8 & HWH PP 111 & B & -0.021 & 0.102 & 0.047 & 0.029 & -0.045 & & 0.02 & & & & 0.846 \\
\hline & 8 & НWHPP 111 & $\mathrm{t}$ & -22.68 & 101.94 & 47.3 & 22.14 & -30.267 & & 20.672 & & & & 0.846 \\
\hline & 0 & НWHNN 111 & B & 0.077 & -0.133 & 0.175 & -0.77 & -0.36 & & 0.026 & & & & 84 \\
\hline & 9 & HWHNN 111 & $\mathrm{t}$ & 39.64 & -61.78 & 81.37 & -25.33 & -11.26 & & 12.69 & & & & 0.184 \\
\hline 4,102 & 10 & HWHSH NNNN 1111 & B & 0.028 & -0.024 & 0.044 & -0.006 & 0.106 & & & & & & 0.713 \\
\hline & & & $\mathrm{t}$ & 34.82 & -52.22 & 85.76 & -12.18 & 63.8 & & & & & & \\
\hline & 1 & HWH TT 141 & B & 0.199 & -0.002 & -0.132 & -0.019 & -0.107 & -0.099 & & & & 0.044 & 077 \\
\hline & 1 & חVV 11141 & $\mathrm{t}$ & 100.24 & -28.74 & -103.83 & -15.29 & -74.07 & -9.13 & & & & 23.33 & $0 . / 83$ \\
\hline & 2 & HWHTT 131 & B & 0.122 & -0.029 & -0.074 & -0.021 & -0.06 & -0.008 & & & & 0.028 & 0794 \\
\hline & 2 & НWH ТТ 151 & $\mathrm{t}$ & 107.85 & -45.97 & -101.71 & -17.96 & -75.52 & -13.19 & & & & 25.55 & 0.194 \\
\hline & 3 & HWHTT 121 & B & 0.173 & -0.039 & -0.107 & -0.026 & -0.082 & -0.017 & & & & 0.039 & 0776 \\
\hline & & & $\mathrm{t}$ & 101.54 & -40.55 & -98.18 & -15.89 & -68.18 & -18.01 & & & & 24 & 0.170 \\
\hline & 4 & HWH TT 111 & B & 0.169 & -0.059 & -0.077 & -0.033 & -0.076 & -0.013 & & & & 0.029 & 0701 \\
\hline : & 4 & HWH IIIII & $\mathrm{t}$ & 144.07 & -71.01 & -81.16 & -17.72 & -70.84 & -15.09 & & & & 21.8 & 0.191 \\
\hline I & 5 & HWH PP 141 & B & 0.007 & 0.035 & 0.025 & 0.045 & -0.029 & 0.002 & & & & 0.004 & 0.57 \\
\hline نं & $J$ & НWHPP 141 & $\mathrm{t}$ & 5.06 & 39.48 & 28.92 & 39.14 & -29.88 & 2.21 & & & & 3.95 & $0.5 /$ \\
\hline & 6 & HWH PP 131 & B & -0.005 & 0.043 & 0.02 & 0.034 & -0.028 & 0.001 & & & & 0.002 & 0.758 \\
\hline & & & $\mathrm{t}$ & -6.28 & 76.68 & 39.85 & 30.18 & -50.91 & 2.73 & & & & 3.77 & \\
\hline & 7 & HWH PP 121 & B & -0.006 & 0.052 & 0.039 & 0.03 & -0.049 & -0.002 & & & & & $077^{2}+3$ \\
\hline & 1 & ПWПनि 121 & $t$ & -6.98 & 64.5 & 41.87 & 34.11 & -47.53 & -3.07 & & & & & 0.1 \\
\hline & 8 & HWH PP 111 & B & -0.033 & 0.096 & 0.065 & 0.029 & -0.063 & 0.005 & & & & 0.008 & 0746 \\
\hline & 8 & НWHPP 111 & $\mathrm{t}$ & -14.37 & 74.68 & 44.33 & 24.4 & -38.08 & 3.55 & & & & 3.74 & 0.140 \\
\hline & 9 & HWH NN 111 & B & 0.114 & -0.087 & 0.149 & -0.026 & -0.043 & -0.012 & & & & -0.026 & 0713 \\
\hline & & & $\mathrm{t}$ & 44.17 & -59.56 & 89.38 & -16.52 & -22.91 & -8.16 & & & & -10.74 & \\
\hline 6,043 & 10 & HWHSH NNNN 111 & B & 0.025 & -0.034 & 0.055 & -0.004 & 0.155 & -0.023 & & & & & 0765 \\
\hline & 10 & HW HSH NINNN 1111 & $t$ & 33 & -59.42 & 90.76 & -14.65 & 75.66 & -12.79 & & & & & $0 . / 65$ \\
\hline
\end{tabular}

Individuals that have cars in the household predominantly use automobiles (PP) for traveling between the locations of their activities. Thus, the coefficients for the variable AUT are positive for the travel patterns with car usage: HWH PP 141 (industry (0.047); commerce (0.035)); HWH PP 131 (industry (0.053); commerce (0.043)); HWH PP 121 (industry (0.068); commerce (0.052)); HWH PP 111 (industry (0.102); commerce (0.096)).

The models with transit usage (HWH TT 141, HWH TT 131, HWH TT 121, and HWH TT 111) verify that the negative contribution of the variable "AUT" decreases (in absolute value) as travel distances increase ("111" - larger contribution of the variable AUT; "141" - smaller contribution of the variable "AUT"). This result corroborates the previous observation that individuals with cars in the household often choose transit for the accomplishment of longer trips ("141”). 
Table 3 - Dummy independente variables

\begin{tabular}{|c|c|c|c|}
\hline \multicolumn{2}{|c|}{ Dummy variables } & \multicolumn{2}{|c|}{ values } \\
\hline Description & code & $\mathbf{0}$ & 1 \\
\hline car ownership & AUT & $\mathrm{AUT}=0$ & AUT $>=1$ \\
\hline Transit Pass Ownership & $\mathrm{TP}$ & $\mathrm{TP}=1$ (use) & $\mathrm{TP}=2$ (do not use) \\
\hline \multirow{2}{*}{ Household Income } & HI (IND) & HI $($ IND) $<2970$ & HI $($ IND $) \geq 2970$ \\
\hline & $\mathrm{HI}(\mathrm{COM})$ & $\mathrm{HI}(\mathrm{COM})<2260$ & $\mathrm{HI}(\mathrm{COM}) \geq 2260$ \\
\hline Study & STUDY & STUDY=1(No) & STUDY $>1$ (Yes) \\
\hline work & WORK & WORK = 1 (Employee $)$ & WORK=2 (Autonomous) \\
\hline $\begin{array}{c}\text { accumulated opportunities in } \\
\text { the industry sector until } \\
5 \mathrm{~km} \text { from the Home } \mathrm{TZ} \\
\end{array}$ & IND $5 \mathrm{~km}$ & IND $5 \mathrm{~km}<3.2$ & IND $5 \mathrm{~km}>3.2$ \\
\hline $\begin{array}{c}\text { accumulated opportunities in } \\
\text { the industry sector until } \\
10 \mathrm{~km} \text { from the Home } \mathrm{TZ} \\
\end{array}$ & IND $10 \mathrm{~km}$ & IND $10 \mathrm{~km}<15.6$ & IND $10 \mathrm{~km}>15.6$ \\
\hline $\begin{array}{c}\text { accumulated opportunities in } \\
\text { the industry sector until } \\
15 \mathrm{~km} \text { from the Home } \mathrm{TZ} \\
\end{array}$ & IND $15 \mathrm{~km}$ & IND $15 \mathrm{~km}<32.3$ & IND $15 \mathrm{~km}>32.3$ \\
\hline $\begin{array}{l}\text { accumulated opportunities in } \\
\text { the commerce sector until } \\
5 \mathrm{~km} \text { from the Home } \mathrm{TZ}\end{array}$ & COM $5 \mathrm{~km}$ & COM $5 \mathrm{KM}<0.008$ & COM $5 \mathrm{~km}>0.008$ \\
\hline
\end{tabular}

In the models for automobile usage (HWH PP 141, HWH PP 131, HWH PP 121 and HWH PP 111), the contribution of the variable "AUT" is greater for shorter travel distances, such as HWH PP 111. Frequently, people choose driving short distances instead walking when they have cars in the household.

The results obtained through CART application suggest that individuals that are studying (and are workers in the industry or commerce sector) perform activity sequences related to work and school - (variable - "Study").

In such a way, individuals who are studying and working (variable "Study" equal to unity) accomplish travel patterns with trip purposes related to Work and School (HWHSH). A positive contribution in the two samples for this variable in the model HWHSH NNNN 1111 (industry (0.106); commerce (0.155)) was observed. 
People who do not use TP (value one for the variable "Transit Pass Ownership") predominantly do not use transit in the travel mode sequence. Thus, the coefficients for this variable are highly negative in the models with transit usage: HWH TT 141 (industry (0.109); commerce (- 0.132)); HWH TT 131 (industry (- 0.089); commerce (- 0.074)); HWH TT 121 (industry (- 0.099); commerce (- 0.107)); HWH TT 111 (industry (- 0.090); commerce $(-0.077))$.

The importance of this variable in choice of travel mode, especially related to transit usage, is evident. The estimated coefficient values for this variable confirm the previous results obtained using the CART application.

Positive estimated values of the coefficients are found in the case of the models associated with automobile or walking choices (PP and NN): HWH PP 141 (industry (0.024); commerce (0.025)); HWH PP 131 (industry (0.019); commerce (0.020)); HWH PP 121 (industry (0.027); commerce (0.039)); HWH PP 111 (industry (0.047); commerce (0.065)); HWH NN 111 (industry $(0.175)$; commerce $(0.149))$.

As noted previously, individuals with high Household Incomes frequently use cars in their trip sequences. Thus, Household Incomes greater than or equal to R $\$ 2970$ (industry sector workers) or R \$ 2260 (commerce sector workers) - (variable "Household Income"- HI equal to unity) contribute negatively to the fulfillment of the travel patterns involving transit and non-motorized usage (TT or NN): HWH TT 141 (industry (- 0.025); commerce (- 0.019)); HWH TT 131 (industry (- 0.030); commerce (- 0.021)); HWH TT 121 (industry (- 0.055); commerce (- 0.026)); HWH TT 111 (industry (- 0.058); commerce (- 0.033)); HWH NN 111 (industry (-0.770); commerce (-0.026)).

Otherwise, positive values for the coefficients associated with the models (travel patterns) with car usage (PP) were observed: HWH PP 141 (industry (0.099); commerce (0.045)); HWH PP 131 (industry (0.039); commerce (0.034)); HWH PP 121 (industry (0.031); commerce (0.030)); HWH PP 111 (industry (0.029); commerce (0.029)).

Moreover, it is also evident that the contribution of the variable HI increases with travel distance. This value is larger for long travel distances such as " 141 ". This result confirms the 
conclusion that people with high incomes not only use predominantly automobiles but also carry out longer trips.

The high value for the "Land Use" variable in the model HWH TT 141 (industry sector workers) indicates the importance of this variable in destination choices. Individuals that live in TZs with high accumulated industry opportunities (IND $5 \mathrm{~km}>3.22 \%$ ) are more disposed to carry out short trips. Thus, if the variable "IND 5km" assumes value one (5 IND km > $3.22 \%$ ), this strongly and negatively influences the accomplishment of the travel pattern HWH TT 141 (travel distances above of $15 \mathrm{~km}$ - Destination/travel distance sequences 141).

In the model pattern HWH TT 131 (industry sector workers), if the variable IND 10km has a value of 1 (10 IND $\mathrm{km}>15.6 \%)$ there is a negative influence $(-0.046)$ on the fulfillment of the travel pattern HWH TT 131. Individuals that live in TZs with high accumulated industry opportunities until $10 \mathrm{~km}$ from the centroid predominantly carry out travel distances shorter than $10 \mathrm{~km}$ and not between 10 and $15 \mathrm{~km}$ ("131").

In the sample of commerce sector workers, smaller influences of the land use variables were observed. The biggest value of the parameter associated with the land use variable was 0.044 for the variable "COM $5 \mathrm{~km}$ " in model HWH TT 141. This confirms that the influence of the land use for the case of commerce sector workers is not strong.

\section{Conclusion}

This research confirmed two main hypotheses: (1) it is possible to find relationships between urban travel patterns (dependent variable) and socioeconomic characteristics, land use and out-of-home activity participation; and (2) the different spatial distributions of economic activities (commercial and industrial) in the urban environment influence the travel of commerce or industry sector workers.

In the first and second parts of this article (exploratory and confirmatory analysis, respectively), relations were found between variables using CART algorithms and confirmed through the measurement of the statistical significances of the independent variables using Multiple Linear Regression (MLR). 
This study has some limitations related to the methodology application, such as: (1) constraint of travel patterns number by the statistical package used (S-PLUS 6.1), (2) Lack of data related to the spatial distribution for other activities beyond industrial and commercial, (3) use of centroid distances of Traffic Zones.

The results obtained allowed for detailed analysis of the influence of the three variable groups on travel patterns: (1) socioeconomic variables (Household Income, Transit Pass Ownership , Car-ownership) appear to affect the travel mode sequence used for trips; (2) activity participation (Study, Work) is important for the trip purpose sequence; and (3) land use variables (accumulated proportion of jobs by distance buffers starting from the residence zone centroid) has a significant influence on the sequence of chosen destinations. It is expected that the results of this research can be used to represent the level of activities and their geographic distribution in the urban configuration (land use variables) and to determine the influence of such variables on commerce and industry sector worker travel.

The SPMA has experienced an increase in jobs in the tertiary sector in recent years, to the detriment of jobs in the industry sector. These changes in the job market can modify travel patterns. In this work, travel behavior differences between industry and the commerce sector workers, governed by the geographic distribution of such activities, are investigated.

\section{Acknowledgments}

This work was partially supported by the Fundação para Ciência e Tecnologia (FCT). The authors are grateful to Companhia do Metropolitano de São Paulo (METRÔ-SP) for the data of the Origin-Destination survey. 


\section{References}

Arentze, T., Hofman V, Mourik van, H. and Timmermans, H. (2000). ALBATROSS: Multiagent, Rule-Based Model of Activity Pattern Decisions. In Transportation Research Record: Journal of the Transportation Research Board, No 1706, Transportation Research Board of the National Academies, Washington, D.C, pp. 136-144.

Balasubramaniam, C. and Goulias, K. (1999) Exploratory longitudinal analysis of solo and joint trip making. 78th Annual Meeting of Transportation Research Board. Compendium of Papers CDROM, 1999, Washington, D.C.

Bhat, C.R. and Singh, S.K (2000) A comprehensive daily activity-travel generation model system for workers. Transportation Research Part A, v.34, pp.1-22.

Bhat C.R. and Koppelman , F.S (1991) A conceptual framework of individual activity program generation. Transportation Research Part A, v. 27, 1991, pp.433-446.

Breiman, L., Friedman J.H, Olshen, R.A. and Stone, C.J. (1984). Classification and Regression Trees. Wadsworth International Group, California.

Bowman, J.L. and Ben-Akiva, M.E. (2000) Activity-based disaggregate travel demand model system with activity schedules. Transportation Research Part A, v.35, pp.1-28.

Cervero, R. and Radisch, M.E. (1996). Pedestrian versus automobile oriented neighborhoods. Transport Policy, v.3, pp.127-141.

Ewing, R. (1995) Beyond density, mode choice, and single-purpose trips. Transportation Quarterly, v.49, pp. 16-23.

Golob, T.F and Mcnally, M. (1997) A model of activity participation and travel interactions between household heads. Transportation Research Part B, v.31, pp.177-194.

IBGE - INSTITUTO BRASILEIRO DE GEOGRAFIA E ESTATÍSTICA. Censo Demográfico 2000. Características urbanísticas em torno dos domicílios. Rio de Janeiro: Ministério do Planejamento, Orçamento e Gestão, 2000. In portuguese.

Kitamura, R., Mokhtarian, P.L and Laidet, L. (1997). A micro-analysis of land use and travel in five neighborhoods in the San Francisco Bay Area., Transportation, n. 24, pp. 125-158.

Kwan M. (2000) Interactive revisualization of activity-travel patterns using three-dimensional geographical information systems: a methodological exploration with a large data set. Transportation Research Part C, v.8, pp.185-203.

Lu, X. and Pas, E.I. (1999). Socio-demographics, activity participation and travel behavior. Transportation Research Part A, v.33, pp.1-18.

Mcguckin, N. and Murakami, E. (1999) Examining trip-chaining behavior: Comparison of travel by men and women. In Transportation Research Record: Journal of the Transportation Research Board, No 1693, Transportation Research Board of the National Academies, Washington, D.C, pp. 79-85.

METRO (2000) Pesquisa Origem Destino 1997 - Região Metropolitana de São Paulo: Síntese das informações. In portuguese.

Piramuthu, S. (2008) Input data for decision trees. Expert Systems with applications, v.34, pp. 12201226.

Schneider, M (1959). Gravity models and trip distribution theory. Papers and Proceedings of the Regional Science Association, v.5, p.51-56. 
Simma, A. and Axhausen, K.W. (2001) Within household allocation of travel: the case of upper Austria. In Transportation Research Record: Journal of the Transportation Research Board, No 1752, Transportation Research Board of the National Academies, Washington, D.C, pp. 69-75.

Srinivasan, K.K. and Athuru, S.R. (2005). Analysis of within-household effects and between household differences in maintenance activity allocation. Transportation, v.32, pp.495-521.

Strambi, O., Vespucci, K.M and van de Bilt, K. (2004) Analysis of the evolution of classes of individual patterns and their relation to socio-demographic and economic variables. $83^{\text {rd }}$ Annual Meeting of Transportation Research Board. Compendium of Papers CD-ROM, Washington, D.C.

Strathman, J.G., and Dueker, K.J. (1990). Understanding Trip Chaining. 1990 NPTS Special Reports on Trip and Vehicle Attributes. Publication FHWA-PL-95-033. FHWA, U.S Department of Transportation. 